\title{
Thermal Expansion of Binary Alkaline-Earth Borate Glasses
}

\author{
Herman F. Shermer
}

\begin{abstract}
The thermal expansivity of a number of calcium, strontium, and barium borate glasses are reported. The expansivity of the calcium and strontium borates increases with increasing alkaline-earth oxide concentration. The expansivity of the barium borate glasses is a minimum at about 20 mole percent of barium oxide. The expansivity measurements on the glasses were correlated with the density measurements in the liquid range. The expansivity of any composition is the lowest in the glassy (solid) region and is greater in the liquid region. The expansivity in a third region which was described as "very viscous" was not measured but was indicated to be greater than in either of the measureable regions. The density curves for each alkaline-earth borate series converges with increasing temperature.
\end{abstract}

\section{Introduction}

A study of the thermal expansion of the binary alkaline-earth borate glasses was undertaken as part of a comprehensive investigation of various physical properties of simple glass-forming systems. This report is the third of a series on the relationships between chemical composition and physical properties of the binary alkaline-earth borates. The first report [1] ${ }^{1}$ was mainly concerned with the properties of the molten compositions, such as viscosity and surface tension, and the second [2] was concerned with the compressibility of the alkaline-earth borate glasses.

The plan of the present work was the determination of the relative effects of varying amounts of calcium, strontium, and barium oxides on the thermal expansion of borate glasses. It was desired to study these relationships over as wide a composition range as possible, but the region of glass formation was limited at low alkaline-earth oxide concentrations by the formation of two immiscible liquids, and at high concentrations by crystallization $[4,5]$.

\section{Preparation of Glasses and Method of Test}

The glasses investigated were made by melting the required amounts of reagent-grade chemicals in platinum crucibles at approximately $1,300^{\circ} \mathrm{C}$. The alkaline-earth oxides were introduced to the batch in the form of carbonates, and the boric oxide was added as boric acid. The melts, which weighed approximately 500 grams, were stirred with a propellor-type platinum stirrer until they appeared clear (at least 1 hour), and then they were poured into a cold iron mold. These binary glasses were later annealed by holding them at $590^{\circ} \mathrm{C}$ for 3 hours and then cooling them at $3 \mathrm{deg} \mathrm{C}$ per hour for 30

\footnotetext{
1 Figures in brackets indicate the literature references at the end of this paper.
}

hours, after which the power to the furnace was shut off, and the glasses were allowed to cool to room temperature. Polariscopic examination of the specimens revealed a slight amount of strain in the calcium borate glasses, but this strain was not detected in the expansion curves. The presence of strain is normally indicated by a decrease in the expansion with increase in the temperature in the range just below the point at which rapid expansion begins. The samples used in the determination of thermal expansion were cut from cylinders (approximately $1 / 2$ in. in diameter and 3 in. long) that had been used for compressibility specimens in previous work [2].

Bridgman and Simon [3] have shown that a compaction of fused $\mathrm{B}_{2} \mathrm{O}_{3}$ occurs during compression measurements. As the glasses used in this study had been used previously for compressibility measurements and contained 63 to 84 mole percent of $\mathrm{B}_{2} \mathrm{O}_{3}$, one must consider the possibility that such compactions may have occurred. Weir and Shartsis [2] report a decrease in volume during compression testing on the order of 0.2 percent and also report it as being independent of $\mathrm{B}_{2} \mathrm{O}_{3}$ concentration. An increase of this magnitude was attributed to experimental error. Even if this compaction were real, it is believed that its magnitude is too small to seriously affect the expansion data. Bridgman and Simon [3] have indicated that time and/or temperature may be employed to restore the specimens to their original densities. In the present investigation it is believed that the period between the compressibility measurements and expansion measurements (approximately 6 months) and the heating of the specimens to $200^{\circ} \mathrm{C}$ preparatory to measurement minimized any possible effect of the previous compression measurements. An adjacent portion of the specimen was removed and analyzed by triple evaporation with $\mathrm{HF}$ and $\mathrm{H}_{2} \mathrm{SO}_{4}{ }^{2}{ }^{2}$

${ }^{2}$ The compositions were analyzed by Ernest B. Clark, formerly of the staff of the National Bureau of Standards. 
Following the original determination of thermal expansion, an adjacent portion of the four samples of calcium borate glasses that showed strain was reannealed to determine what differences, if any, would be observed in the thermal-expansion curves. These glasses were reannealed by heating them to $655^{\circ} \mathrm{C}$ for 3 hours. They were then cooled at approximately 3 deg $\mathrm{C}$ per hour until they reached $455^{\circ} \mathrm{C}$ ( 68 hours), after which they were allowed to cool in the sealed furnace, with no further application of power.

The measurements of thermal expansion were made by the interferometer method of Peters and Cragoe [6] as modified by Saunders [7]. The test specimen was formed into a $T$-shaped spacer about $5 \mathrm{~mm}$ high, which was placed between two optically flat Vycor disks, the lower one of which served as an interference thermometer. This "sandwich" was placed in a metal cup with a fused-silica top to decrease any temperature gradients. This cup was placed within a resistance-type electric furnace, which was heated at $2 \mathrm{deg} \mathrm{C}$ per minute from room temperature to above the deformation point. The motion of the two sets of fringes, one set formed within the lower plate, which indicated the temperature, and the other formed between the two plates, which indicated the expansion, was recorded on photographic film, and the results were read from this film.

\section{Results and Discussion}

\section{1. $\mathrm{B}_{2} \mathrm{O}_{3}$}

In the study of the expansivity of the binary alkaline-earth borate glasses, it seemed desirable to know the coefficient of linear expansion and other characteristics of the expansion curve for boric oxide $\left(\mathrm{B}_{2} \mathrm{O}_{3}\right)$ glass. Published data on the expansion of this glass are conflicting, as shown in the reviews of the subject by Morey [8] and Karkhanavala [9]. The differences seem to be caused primarily by different melting schedules and heat treatments and, as a result of this, differences in the amount of associated water [10]. Some of this water is retained from the boric acid, and other water may be adsorbed from the atmosphere after the glass is cooled. In order to reduce this water to an amount comparable with the other glasses measured in this investigation, the boric oxide glass was melted on the same schedule as the binary glasses, and all glasses were stored in kerosine. Each sample was cut and dried by heating to $200^{\circ} \mathrm{C}$ and then allowed to cool in the furnace overnight, and the expansion was determined the following day. The results of the determinations are shown graphically in figure 1 and are included for comparison in table 1 . The small hump in the thermal expansion curve for $\mathrm{B}_{2} \mathrm{O}_{3}$ at about $160^{\circ} \mathrm{C}$ is indicative of the small amount of water present [9].

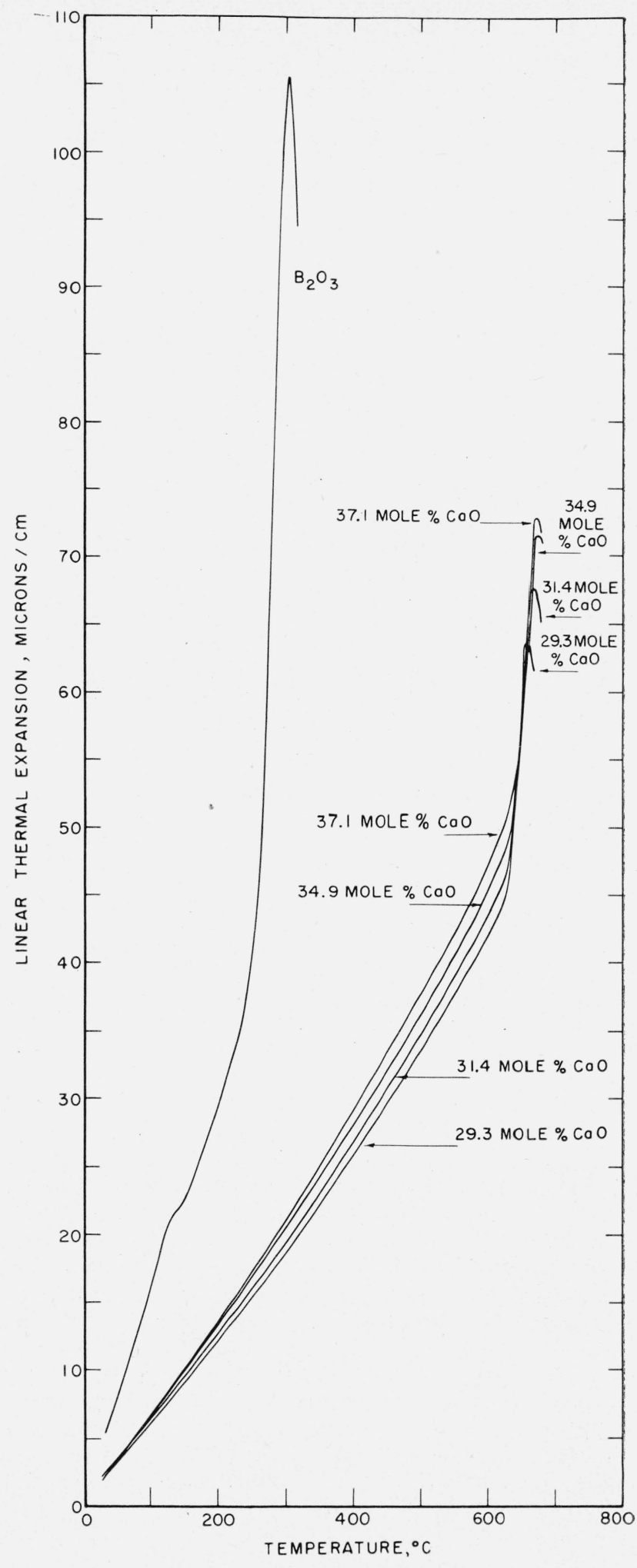

FIGURE 1. Linear thermal expansion of some binary calcium borate glasses and fused $\mathrm{B}_{2} \mathrm{O}_{3}$. 
TABLE 1.-Thermal expansivity of binary alkaline-earth borate glasses

\begin{tabular}{|c|c|c|c|c|c|c|c|c|c|c|}
\hline \multicolumn{2}{|c|}{ Chemical composition } & \multirow{2}{*}{$\begin{array}{l}\text { Density } \\
\text { (room } \\
\text { temp) }\end{array}$} & \multirow{2}{*}{$\begin{array}{c}\text { Critical } \\
\text { temp }\end{array}$} & \multirow{2}{*}{$\begin{array}{l}\text { Defor- } \\
\text { mation } \\
\text { temp }\end{array}$} & \multicolumn{6}{|c|}{ A verage coefficients of expansion per degree $\mathrm{C}$ at $-\mathrm{a}$} \\
\hline RO & RO & & & & Room to $100^{\circ} \mathrm{C}$ & $100^{\circ}$ to $200^{\circ} \mathrm{C}$ & $200^{\circ}$ to $300^{\circ} \mathrm{C}$ & $300^{\circ}$ to $400^{\circ} \mathrm{C}$ & $400^{\circ}$ to $500^{\circ} \mathrm{C}$ & $500^{\circ}$ to $600^{\circ} \mathrm{C}$ \\
\hline \multicolumn{11}{|c|}{ Fused $\mathrm{B}_{2} \mathrm{O}_{3}$} \\
\hline $\begin{array}{c}\text { Mole } \% \\
0.0\end{array}$ & $\begin{array}{l}w t \% \\
0.0\end{array}$ & $\begin{array}{l}\mathrm{g} / \mathrm{cm}^{3} \\
\quad 1.859\end{array}$ & $\begin{array}{l}{ }^{\circ} \mathrm{C} \\
260\end{array}$ & $\begin{array}{l}{ }^{\circ} \mathrm{C} \\
305\end{array}$ & $16.16 \times 10^{-6}$ & 13. $77 \times 10^{-6}$ & & & & \\
\hline \multicolumn{11}{|c|}{$\mathrm{CaO}-\mathrm{B}_{2} \mathrm{O}_{3}$} \\
\hline $\begin{array}{l}29.3 \\
31.4 \\
34.9 \\
37.1\end{array}$ & $\begin{array}{l}25.0 \\
27.0 \\
30.2 \\
32.3\end{array}$ & $\left\{\begin{array}{r}2.484 \\
\text { Reannealed } \\
2.531 \\
\text { Reannealed } \\
2.595 \\
\text { Reannealed } \\
2.633 \\
\text { Reannealed }\end{array}\right.$ & $\begin{array}{l}633 \\
646 \\
647 \\
649 \\
648 \\
656 \\
643 \\
657\end{array}$ & $\begin{array}{l}658 \\
662 \\
665 \\
665 \\
668 \\
668 \\
669 \\
669\end{array}$ & $\begin{array}{l}\text { 5. } 64 \times 10^{-6} \\
5.49 \\
5.73 \\
5.82 \\
6.01 \\
6.62 \\
6.40 \\
6.31\end{array}$ & $\begin{array}{l}6.08 \times 10^{-6} \\
6.02 \\
6.51 \\
6.35 \\
6.76 \\
6.75 \\
7.04 \\
6.84\end{array}$ & $\begin{array}{l}6.54 \times 10^{-6} \\
6.39 \\
6.74 \\
6.81 \\
7.52 \\
7.47 \\
7.46 \\
7.58\end{array}$ & $\begin{array}{l}7.16 \times 10^{-6} \\
7.13 \\
7.67 \\
7.65 \\
7.78 \\
7.85 \\
8.22 \\
8.16\end{array}$ & $\begin{array}{l}7.69 \times 10^{-6} \\
7.71 \\
7.92 \\
8.10 \\
8.38 \\
9.50 \\
8.69 \\
8.76\end{array}$ & $\begin{array}{l}8.68 \times 10^{-6} \\
8.09 \\
8.85 \\
8.31 \\
9.18 \\
9.21 \\
9.55 \\
9.35\end{array}$ \\
\hline \multicolumn{11}{|c|}{$\mathrm{SrO}-\mathrm{B}_{2} \mathrm{O}_{3}$} \\
\hline $\begin{array}{l}21.4 \\
21.8 \\
25.0 \\
26.9 \\
28.5 \\
30.5 \\
33.3\end{array}$ & $\begin{array}{l}29.0 \\
29.4 \\
34.4 \\
35.5 \\
37.3 \\
39.6 \\
42.6\end{array}$ & $\begin{array}{r}2.649 \\
2.677 \\
2.802 \\
2.852 \\
\text { \{emeasured } \\
2.931 \\
3.007 \\
3.101\end{array}$ & $\begin{array}{l}598 \\
604 \\
619 \\
620 \\
621 \\
624 \\
628 \\
629\end{array}$ & $\begin{array}{l}614 \\
621 \\
635 \\
638 \\
638 \\
641 \\
649 \\
649\end{array}$ & $\begin{array}{l}\text { 5. } 79 \times 10^{-6} \\
5.77 \\
5.85 \\
6.01 \\
5.97 \\
6.34 \\
6.71 \\
6.96\end{array}$ & $\begin{array}{l}6.22 \times 10^{-6} \\
6.36 \\
6.46 \\
6.58 \\
6.56 \\
6.76 \\
6.96 \\
7.47\end{array}$ & $\begin{array}{l}6.66 \times 10^{-6} \\
6.76 \\
7.03 \\
6.86 \\
7.12 \\
7.24 \\
7.72 \\
8.32\end{array}$ & $\begin{array}{l}7.28 \times 10^{-6} \\
7.40 \\
7.76 \\
7.56 \\
7.67 \\
7.98 \\
8.28 \\
8.49\end{array}$ & $\begin{array}{l}8.04 \times 10^{-6} \\
7.87 \\
8.68 \\
8.12 \\
8.15 \\
8.42 \\
9.26 \\
8.62\end{array}$ & $\begin{array}{r}9.04 \times 10^{-6} \\
9.08 \\
9.42 \\
9.03 \\
10.16\end{array}$ \\
\hline \multicolumn{11}{|c|}{$\mathrm{BaO}-\mathrm{B}_{2} \mathrm{O}_{3}$} \\
\hline $\begin{array}{l}17.3 \\
20.1 \\
23.7 \\
27.1 \\
29.0 \\
31.7 \\
36.0\end{array}$ & $\begin{array}{l}31.6 \\
35.8 \\
40.6 \\
45.1 \\
47.5 \\
50.6 \\
55.4\end{array}$ & $\begin{array}{l}2.678 \\
2.813 \\
2.996 \\
3.190 \\
3.289 \\
3.429 \\
3.630\end{array}$ & $\begin{array}{l}509 \\
561 \\
575 \\
589 \\
587 \\
598 \\
594\end{array}$ & $\begin{array}{l}540 \\
580 \\
595 \\
606 \\
606 \\
610 \\
609\end{array}$ & $\begin{array}{l}6.59 \times 10^{-6} \\
6.19 \\
6.43 \\
6.59 \\
6.82 \\
7.37 \\
7.86\end{array}$ & $\begin{array}{l}6.69 \times 10^{-6} \\
6.59 \\
6.64 \\
6.90 \\
7.46 \\
7.64 \\
8.48\end{array}$ & $\begin{array}{l}\text { 7. } 25 \times 10^{-6} \\
7.01 . \\
7.02 \\
6.01 \\
7.89 \\
8.13 \\
8.91\end{array}$ & $\begin{array}{l}\text { 7. } 80 \times 10^{-6} \\
7.67 \\
7.71 \\
8.14 \\
9.48 \\
8.86 \\
9.68\end{array}$ & $\begin{array}{r}9.77 \times 10^{-6} \\
8.39 \\
8.21 \\
9.36 \\
10.39 \\
9.58 \\
10.74\end{array}$ & - \\
\hline
\end{tabular}

a The estimated accuracy of values of average coefficient of expansion per degree $\mathrm{C}$ is $\pm 0.1 \times 10^{-6}$. The values given contain one additional figure for convenience $\mathrm{n}$ intercomparisons and better determination of greater temperature ranges.

\subsection{Calcium Borates}

The results of the thermal-expansion measurements of the calcium borate glasses are given in table 1 and figure 1. Although the four curves for the calcium borate glasses are similar, certain trends are apparent. The most obvious of these is the increase in expansivity with increasing concentration of calcium oxide. This is true in the region from room temperature to the "critical" temperature and also at the deformation point. The critical temperature is defined here as the approximate temperature at which rapid expansion begins. This is in contrast with the expansion of fused $\mathrm{B}_{2} \mathrm{O}_{3}$, which may be thought of as having the lowest concentration of calcium oxide, and which has the highest expansion. It may also be noted that the temperature of the deformation point increases with increasing calciumoxide concentration. The deformation point is the highest point on an expansion curve obtained by the interferometer method and corresponds to the temperature at which viscous flow exactly counteracts thermal expansion.

The values of the coefficients of expansion of the calcium borates are included in table 1 . Values for the reannealed samples are also given. In general, the reannealed glass had a slightly lower expansion below the critical temperature. It may also be noted that the height of the curve at the deformation point was greater in the reannealed sample, indicating a higher density at room temperature. The samples used for reannealing were not large enough for accurate density determinations.

The apparent increase in density of the calcium borate glasses when reannealed at $655^{\circ} \mathrm{C}$ indicated that the original annealing at $590^{\circ} \mathrm{C}$ was not continued for sufficient time for equilibrium conditions to be established at that lower temperature. It also indicates that the equilibrium condition of the glass before and after the original annealing corresponded to a temperature above the equilibrium condition that was established during the second annealing. The results of the original measurement of thermal expansion are shown in figure 1 . The results of the second determination are in table 1 but because of the small differences in expansivity found upon reannealing the curves are not shown. 


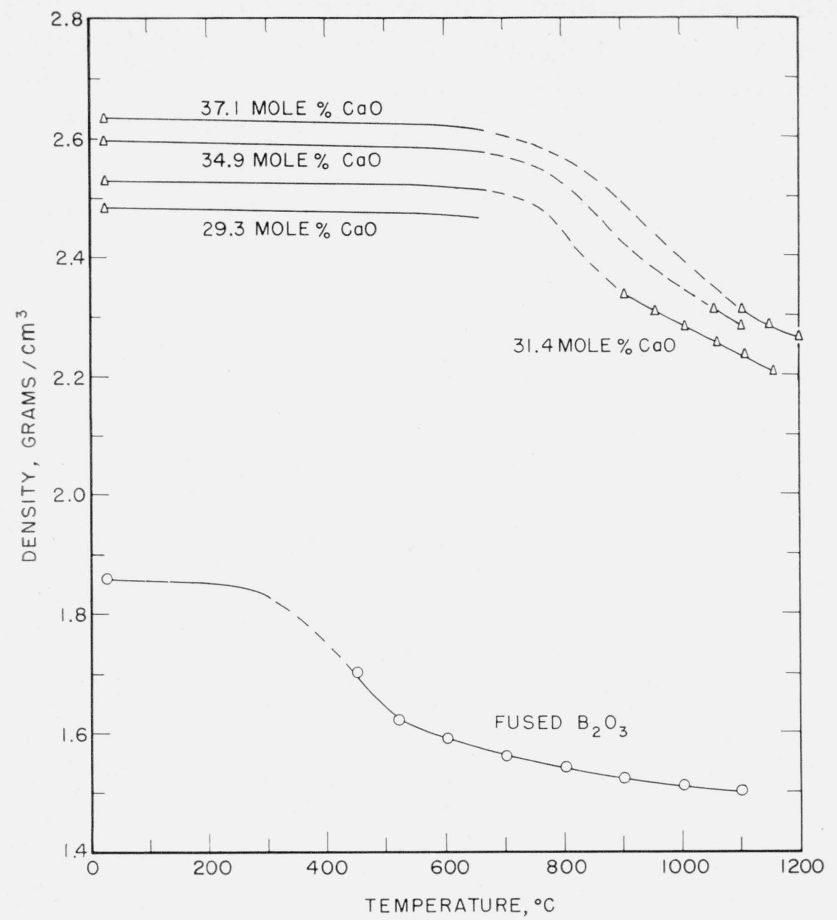

Figure 2. Densities of some binary calcium borate glasses and liquids, with fused and liquid $\mathrm{B}_{2} \mathrm{O}_{3}$, as a function of temperature.

Figure 2 shows the thermal-expansion curves for $\mathrm{B}_{2} \mathrm{O}_{3}$ and the binary calcium borates plotted as change in density with temperature. This method of presenting the data made possible the inclusion of density values in the liquid range that were obtained previously [1]. It has not been possible to obtain density values of the liquids when they are very viscous, but it is hoped that the interpolations are reasonable. Three characteristics of this set of curves are the convergence of the curves with increase in temperature, the greater change in density with temperature in the liquid range than in the solid range, and a middle range in which the glasses have higher coefficients of expansion than in either of the measurable ranges.

\subsection{Strontium Borates}

The thermal expansivity values for 7 strontium borate glasses are given in table 1 and the curves of 4 of them are shown in figure 3. Most of the characteristics of the calcium borate curves are repeated here. The expansivity from room temperature to the critical temperature and the expansivity and temperature at the deformation point all increased with increasing concentration of strontium oxide. Two determinations of the glass containing 26.9 mole percent of $\mathrm{SrO}$ are included in the table to illustrate the reproducibility of the results.

Figure 4 shows the thermal-expansion curves of the strontium borates plotted as part of the densityversus-temperature curves for these compositions.

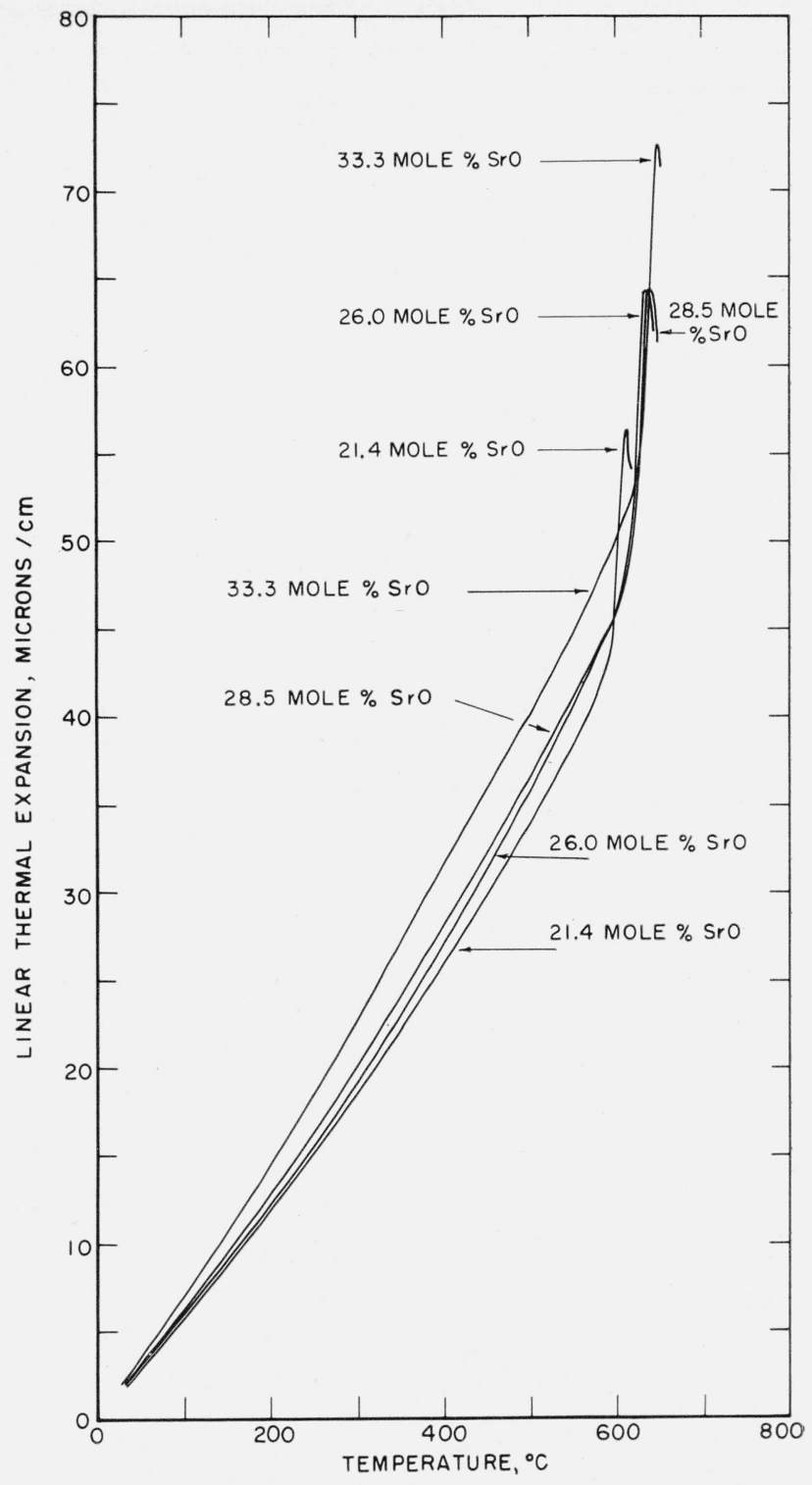

FIgURE 3. Linear thermal expansion of four selected binary strontium borate glasses.

This set of curves shows a behavior similar to that of the calcium borates in its covergence with increasing temperature, higher expansivity in the liquid range, and still higher expansivity in the very viscous range, which was not measured.

\subsection{Barium Borates}

The results of the measurements of thermal expansion of the barium borates are included in table 1 , and the curves of four of them are shown in figure 5. There is one important variation in these results from those found in the calcium and strontium systems. This change is in the relative expansion of the glass containing 20.1 mole percent of $\mathrm{BaO}$ below that of the glass containing 17.3 mole percent of $\mathrm{BaO}$. This decrease in expansivity with increase 


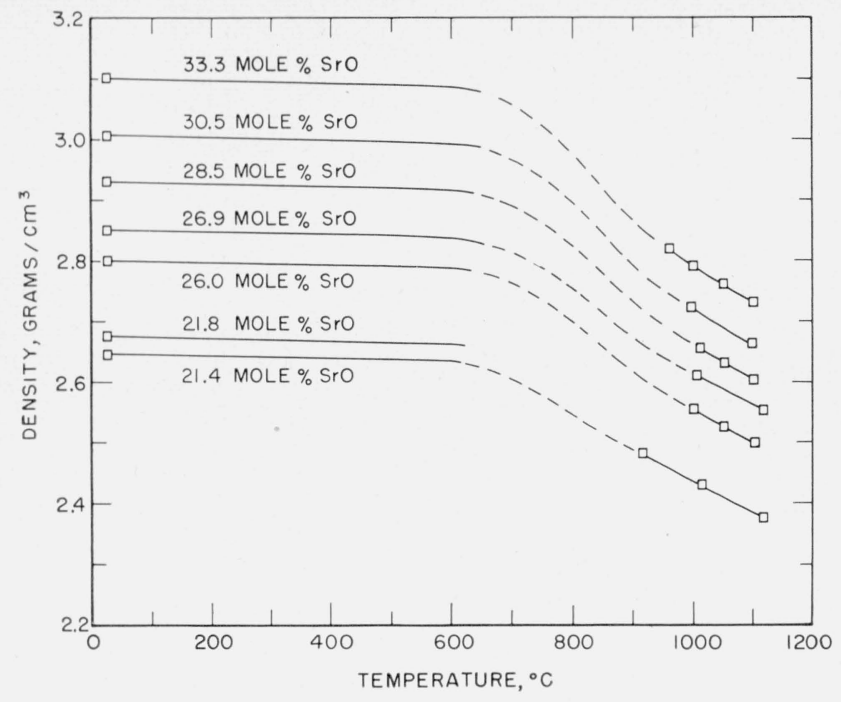

Figure 4. Densities of some binary strontium borate glasses and liquids as a function of temperature.

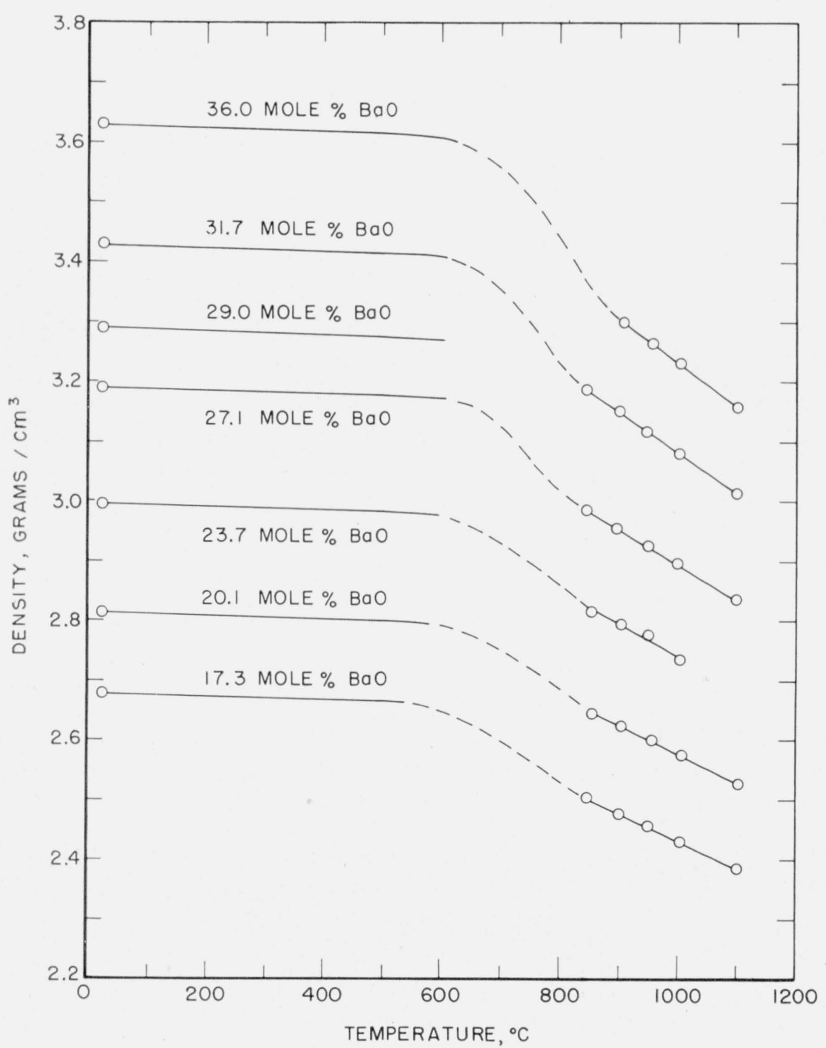

Figure 6. Densities of some binary barium borate glasses and liquids as a function of temperature.

in alkaline-earth oxide concentration is in the same relative direction as the decrease in expansivity between fused $\mathrm{B}_{2} \mathrm{O}_{3}$ and the barium borate glass containing the least amount of $\mathrm{BaO}$. The regions of glass formation of the calcium and strontium borates do not contain minima because of their small compositional range. The glass-forming region of the barium borates, however, is longer and contains

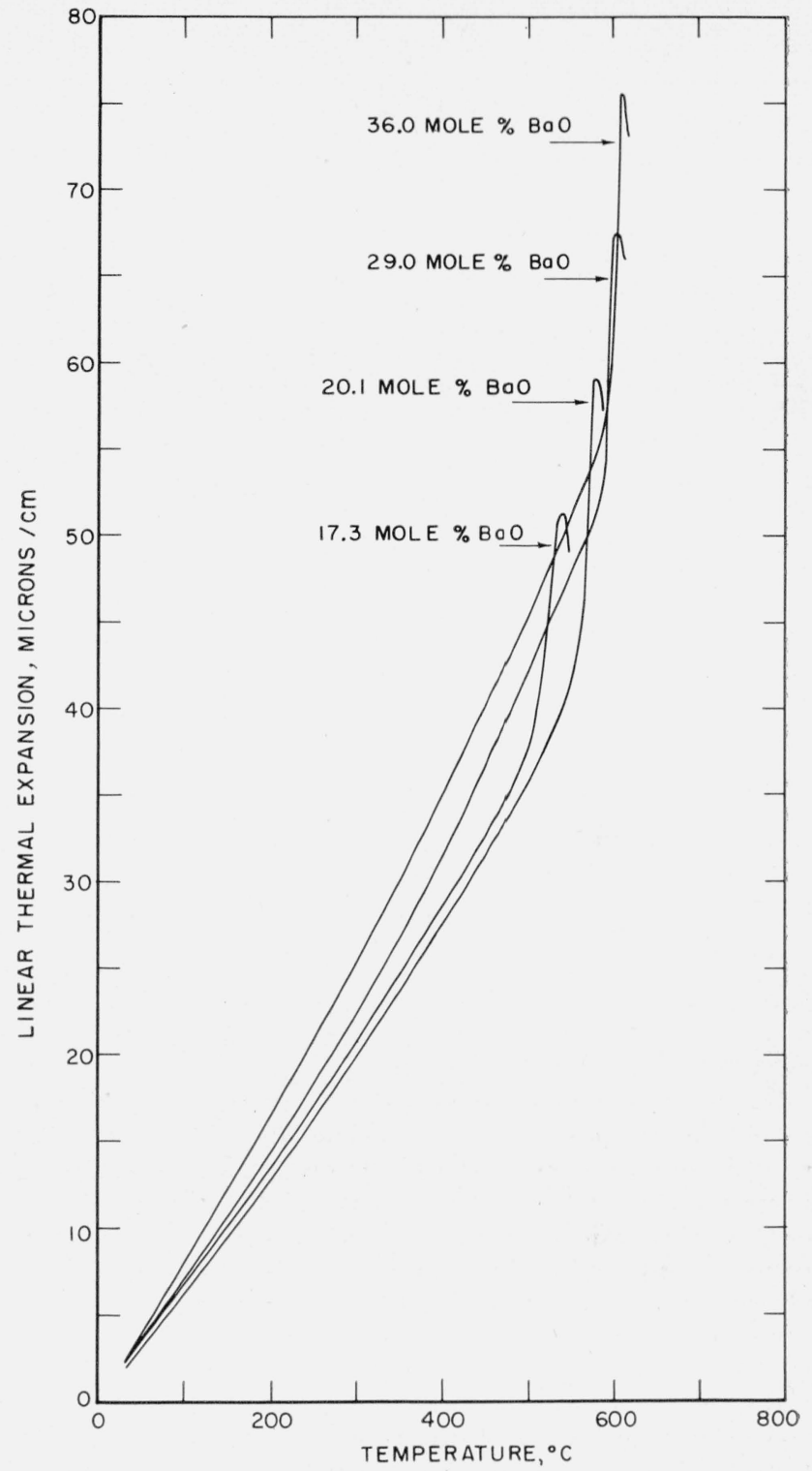

FIGURE 5. Linear thermal expansion of four selected binary barium borate glasses.

the minimum. This minimum is better seen in figure 7. Although the expansivity of the barium borate glasses, below the critical temperature, passed through a minimum in respect to composition, the total expansion from room temperature to the deformation point did not. It may be noted here that the minima in the values of the coefficients of expansion with concentration do not occur at the same point in the various temperature ranges. In general, there seems to be a translation of the minimum to higher barium-oxide concentrations with increase in temperature.

Figure 6 shows the relationship between densities, or expansivities, of the binary barium borates with temperature. The characteristics of this set of curves are similar to those discussed previously for the calcium and strontium borates. 


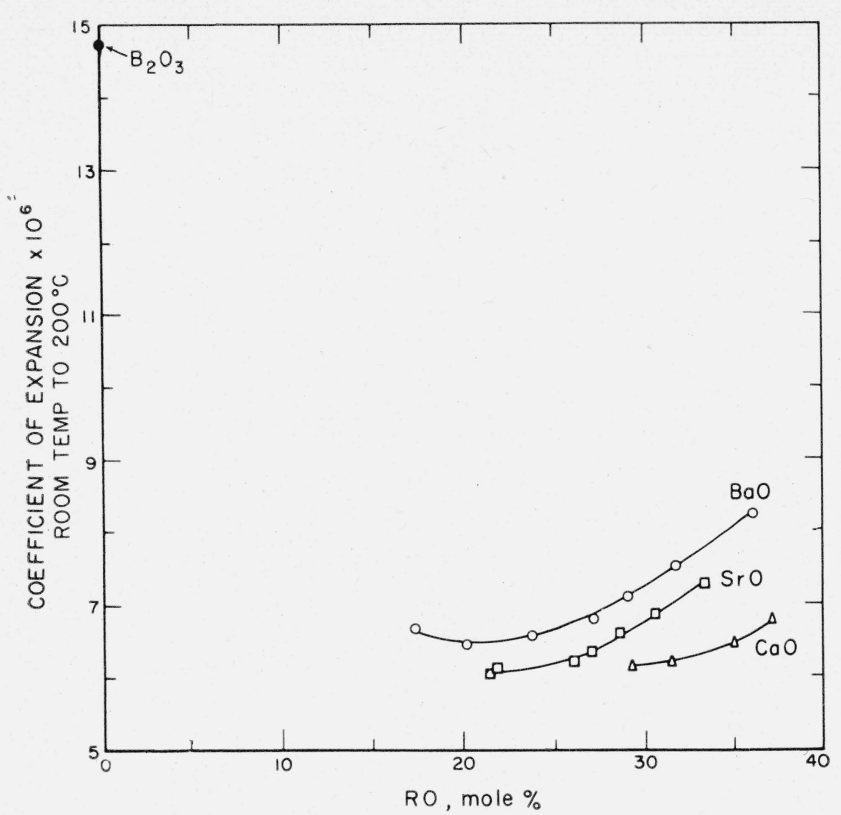

Figure 7. Coefficient of linear thermal expansion as a function of composition of binary alkaline-earth borate glasses and fused $\mathrm{B}_{2} \mathrm{O}_{3}$.

( $\triangle$, calcium borates; $\square$, strontium borates; and $\bigcirc$, barium borates.)

\subsection{Comparison of Thermal Expansivity of Alkaline- Earth Borates}

A comparison of the mean coefficient of expansion over the range from room temperature to $200^{\circ} \mathrm{C}$ of the binary alkaline-earth borate glasses as a function of concentration of alkaline-earth oxide in mole percent is shown in figure 7 . It is apparent that a minimum would have to occur in each of the curves if glasses could be made with lower concentrations of alkaline-earth oxides. There is not sufficient information available to determine the location of the minima in the calcium and strontium curves.

Figure 8 shows a comparison of the deformation temperatures of the binary borate glasses as a function of alkaline-earth oxide concentration in mole percent. These curves show that at comparable compositions the calcium borate glass has the highest temperature at its deformation point, followed by the strontium and then the barium composition. This is in the same order as the melting points of the three alkaline-earth oxides.

\section{Calculation of Thermal Expansion From Composition}

Much work has been done in the past in an effort to find a series of factors from which thermal expansion could be predicted from the composition of various glasses. Sun and Silverman [11] compiled the results of several of these investigations. Among the oxides included in their compilation are three

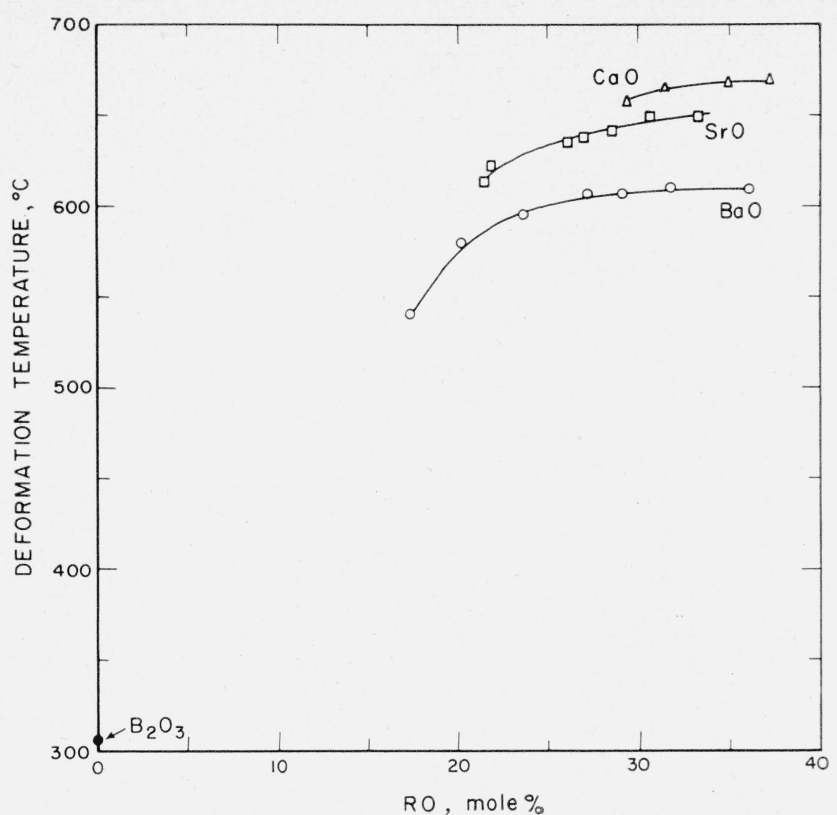

Figure 8. Deformation temperature as a function of composition of binary alkaline-earth borate glasses and fused $\mathrm{B}_{2} \mathrm{O}_{3}$.

$(\triangle$, calcium borates; $\square$, strontium borates; and $\bigcirc$, barium borates.)

that are applicable to the present investigation, namely, $\mathrm{B}_{2} \mathrm{O}_{3}, \mathrm{CaO}$, and $\mathrm{BaO}$. The values assigned to these oxides by various investigators leave much to be desired. Figure 7 shows that the expansionversus-composition curves of the binary alkalineearth borate glasses are not linear, and, therefore, it would seem that in this case the coefficient of thermal expansion is not an additive property.

\section{Coordination of $\mathrm{B}_{2} \mathrm{O}_{3}$}

The thermal expansivities of alkaline-earth borate glasses are of special interest because they exhibit the so-called "boron anomaly"; i. e., they show minima with respect to composition. Warren and Pincus [12] offer an explanation for this anomaly. It con cerns the ability of the boron atom to change from triangular to tetrahedral coordination when an oxide such as $\mathrm{CaO}$ is present and supplies the necessary oxygen. It is believed that fused $\mathrm{B}_{2} \mathrm{O}_{3}$ is triangularly coordinated, and that with the addition of $\mathrm{CaO}$, increasing amounts of boron change to tetrahedral coordination. Stegmaier and Dietzel [13] demonstrated that beyond a point determined by the particular oxides present, any additional content of alkali or alkaline-earth oxides will tend to reverse the process, i. e., change the $\mathrm{B}_{2} \mathrm{O}_{3}$ from fourfold to threefold coordination. A mathematical approach to the problem such as that of Warren and Pincus requires more X-ray data on the particular systems of glasses under study than are now available. An 
alternate approach is from the measurements of physical properties. The measurement of thermal expansion seems to be quite useful in this respect. The minima in the thermal-expansion-composition curves shown in figure 7 are interpreted as indicating maxima in the tetrahedral coordination of $\mathrm{B}_{2} \mathrm{O}_{3}$. This seems to be in accord with the fact that the $\mathrm{BO}_{4}$ tetrahedra tend to strengthen the structure and therefore have a lower expansion.

\section{Summary and Conclusions}

The thermal expansivity of glasses formed in the three binary alkaline-earth borate series was measured. The thermal expansivity of the glasses increased with increasing concentration of calcium or strontium oxide. The expansivity of the binary barium borate glasses went through a minimum with changing concentration of barium oxide. A minimum was implied in the other curves by the high relative expansion of fused $\mathrm{B}_{2} \mathrm{O}_{3}$. It was not found possible to obtain additive factors for the calculation of thermal expansion that would be applicable to these compositions.

The results were correlated with the density values obtained previously in the liquid range in order that the relationship between expansion and temperature could be studied over a greater temperature range. The expansivity of the solid glasses was the lowest, and that of the measurable liquids was much higher. The change in density across the very viscous region was such as to show a still, greater expansivity in this range. The density curves were found to converge with increase in temperature.

\section{References}

[1] Leo Shartsis and H. F. Shermer, Surface tension, density, viscosity, and electrical resistivity of molten binary alkaline-earth borates, J. Am. Ceram. Soc. 37, 544 (1954).

[2] Charles E. Weir and Leo Shartsis, Compressibility of binary alkaline-earth borate glasses, J. Am. Ceram. Soc. (submitted for publication).

[3] P. W. Bridgman and I. Simon, Effects of very high pressures on glass, J. Appl. Phys. 24, 405 (1953).

[4] E. P. Flint and L. S. Wells, The system lime-boric oxidesilica, J. Research NBS 17, 745 (1936) RP941.

[5] Ernest M. Levin and George M. Ugrinic, The system barium oxide-boric oxide-silica, J. Research NBS 51, 37 (1953) RP2430.

[6] C. G. Peters and C. H. Cragoe, Measurements on the thermal dilation of glass at high temperatures, BS Sci. Pap. 16, 449 (1920) S393.

[7] James B. Saunders, An apparatus for photographing interference phenomena, J. Research NBS 35, 157 (1945) RP1668.

[8] G. W. Morey, Properties of glass, 2d ed., p. 273 Am. Chem. Soc. Monograph No. 124 (Reinhold Publishing Corp., New York, N. Y., 1954).

[9] M. D. Karkhanavala, Bibliography of thermal expansion of glasses, Glass Ind. 33, 404 (1952).

[10] James J. Donoghue and Donald Hubbard, Thermal expansion studies of boric oxide glass and crystalline boric oxide, J. Research NBS $\mathbf{2 7}, 371$ (1941) RP1425.

[11] Kuan-Han-Sun and Alexander Silverman, Additive factors for calculating the coefficient of thermal expansion of glass from its composition, Glass Ind. 22, 114,125 (1941).

[12] B. E. Warren and A. G. Pincus, Atomic consideration of immiscibility in glass systems, J. Am. Ceram. Soc. 23, 301 (1940).

[13] W. Stegmaier and A. Dietzel, Die Bedeutung der Basizität von Glasschmelzen und Versuche $\mathrm{zu}$ deren Messung. Teil II, Glastech. Ber. 18, 353 (1940).

Washington, November 1, 1955. 